University for Business and Technology in Kosovo

UBT Knowledge Center

UBT International Conference

2015 UBT International Conference

Nov 7th, 9:00 AM - 5:00 PM

\title{
Application of EC regulations on assessment of the effect of fire on buildings
}

Xhemshir Mulliqi

University of Zagreb, xhemshir_mulliqi@yahoo.com

Follow this and additional works at: https://knowledgecenter.ubt-uni.net/conference

Part of the Civil Engineering Commons, and the Structural Engineering Commons

\section{Recommended Citation}

Mulliqi, Xhemshir, "Application of EC regulations on assessment of the effect of fire on buildings" (2015). UBT International Conference. 69.

https://knowledgecenter.ubt-uni.net/conference/2015/all-events/69

This Event is brought to you for free and open access by the Publication and Journals at UBT Knowledge Center. It has been accepted for inclusion in UBT International Conference by an authorized administrator of UBT Knowledge Center. For more information, please contact knowledge.center@ubt-uni.net. 


\title{
Application of EC regulations on assessment of the effect of fire on buildings
}

\author{
Xhemshir Mulliqi ${ }^{1}$ \\ University of Zagreb, Faculty of Civil Engineering \\ xhemshir_mulliqi@yahoo.com
}

\begin{abstract}
The last decade has been characterized by construction of multi-storey buildings in almost all cities of Kosovo, with the storey -height ranging from $B+G+4$ to $B+G+11$ and even $B+G+15$, which means that they need to be subjected to the revision of the main project,including things be verified for the effect of fire.

This paper aims to illustrate the use of EC regulations for the verification of reinforced concrete structures under effect of fire, respectively:

EN 1991-2-2 Basis of design and actions on structures. Part-2.2: Actions on structures exposed to fire and EN 1992-1-2:2004 Design of concrete structures- part -1-2: Structural fire design.

In this regard, we will review the residential and business object $\mathrm{B}+\mathrm{G}+11$, respectively the complex called "KULLAT" in Mitrovica, the safety assessment of reinforced concrete structures in case of fire The analy sis of certain parts of the structures - beams and columns by applying the tabular method and analy sis of beams with the application of simplified calculation method will be shown.
\end{abstract}

Keywords: Fire calculation, Tabular calculation, simplified calculation method, Cross-section resistance

\section{Introduction}

The comprehensive analysis of reinforced concrete structures under the specified fire scenario includes thermal analysis (determination of temperature distribution within each point of structural elements) and mechanical analysis (evaluation of structural response to determined temperature fields). In order to carry out these analyses, it is necessary to possess detailed information as to numerous material properties (physical, thermal, mechanical -both for structural concrete and for reinforcing steel) which are the functions of temperature [1]

In this regard, we will review the safety assessment of reinforced concrete structures in case of fire for the residential and business object $\mathrm{B}+\mathrm{G}+11$, respectively the complex called "KULLAT" whitch c ontains a basement $2.6 \mathrm{~m}$ high, the ground floor $3.9 \mathrm{~m}$ high and 11 floors $2.9 \mathrm{~m}$ high. In case of an eventual risk of fire, the building height for evacuation is: $3.9+11 \times 2.9=35.8 \mathrm{~m}$. The surface of facade openings: windows and balcony doors per one storey is $: 48,405 \mathrm{~m}^{2}$. The analysis of certain parts of the structures - beams and columns by applying the tabular method and analy sis of beams with the application of simplified calculation method will be shown. Than only the object in a surface of storey $491.84 \mathrm{~m} 2$ will be reviewed. 


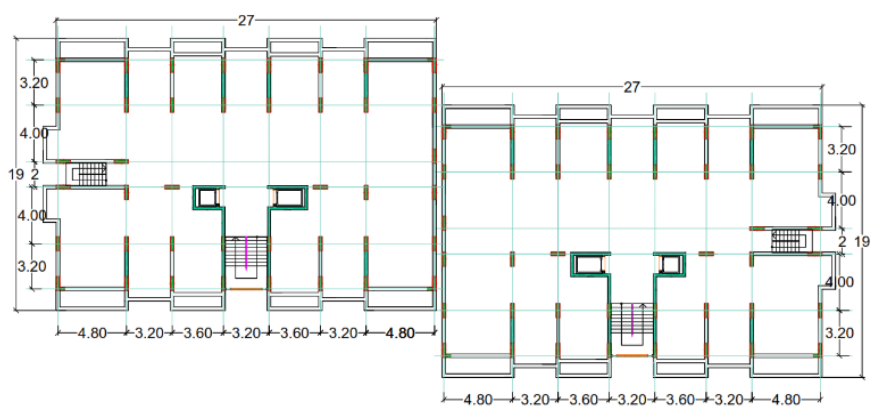

Fig1. The base of the characteristic storey of the object $\mathrm{B}+\mathrm{G}+11$

\section{Values - limit state and load combination}

\subsection{Equation of the value - limit state}

The equation of the limit state is expressed by:

Where:

$$
\mathrm{R}_{\mathrm{fi}, \mathrm{d}, \mathrm{t}} \geq \mathrm{E}_{\mathrm{fi}, \mathrm{d}, \mathrm{t}}
$$

$\mathrm{R}_{\mathrm{fi}, \mathrm{d}, \mathrm{t}}$ design resistance in the fire situation, at time $\mathrm{t}$.

$E_{\mathrm{fi}, \mathrm{d}, \mathrm{t}}$ design effect of actions in the fire situation, at time $\mathrm{t}$. [2]

\subsection{Permanent situation for normal temperature design}

Taking into account only permanent and temporal loads, the following shall apply for the calculation permanent situation:

$$
j \geq 1
$$

$$
\left.\Sigma \gamma_{\mathrm{G}, \mathrm{j}} \cdot \mathrm{G}_{\mathrm{k}, \mathrm{j}}\right)+\gamma_{\mathrm{Q}, 1} \cdot \mathrm{Q}_{\mathrm{k}, 1} ; \quad=1.35 \mathrm{~g}_{\mathrm{k}}+1.5 \cdot \mathrm{q}_{\mathrm{k}}
$$

$\mathrm{G}_{\mathrm{kj}, \mathrm{j}}, \mathrm{Q}_{\mathrm{k}, 1}$ characteristic values of permanent and imposed loads

$\gamma_{\mathrm{G}, \mathrm{j}}, \gamma_{\mathrm{Q}} \quad$ partial factor for permanent actions and for imposed loads

Analysis of permanent loads:

- Reinforced concrete slabs $0.2 \times 25=5.0 \mathrm{Kn} / \mathrm{m} 2 \times(4.8 / 2+3.2 / 2) \quad=20.0 \quad \mathrm{Kn} / \mathrm{m}^{\prime}$

- Beams

$0.35 \times 0.25 \times 25=2.188 \mathrm{Kn} / \mathrm{m}^{\prime}$

- Floor

$1.5 \mathrm{Kn} / \mathrm{m} 2 \times(4.8 / 2+3.2 / 2)=6.0 \quad \mathrm{Kn} / \mathrm{m}^{\prime}$

- Walls

$4 \times 2.7=10,8 \quad \mathrm{Kn} / \mathrm{m}^{\prime}$

Live load $: \mathrm{qk} 1=5.0 \mathrm{x}((4.8 / 2+3.2 / 2)=20 \mathrm{Kn} / \mathrm{m}, \mathrm{qk} 2=2.0 \mathrm{x}((4.8 / 2+3.2 / 2)=8 \mathrm{Kn} / \mathrm{m}$

The dimension of internal beams is $25 / 35 \mathrm{~cm}$, while the dimension of perimetric beams is $25 / 50 \mathrm{~cm}$. The beams are reinforced as shown in the fig 2 . in the bottom area with 3 bars $\mathrm{R} \phi 14 \mathrm{~mm}$ and stirrups $\mathrm{R} \phi 8 \mathrm{~mm} / 20 / 10 \mathrm{~cm}$.

The minimum cover is $2 \mathrm{~cm}$ so that the distance from the bottom of the beam to the axis of the bars is: $20+8+0,5 \cdot 14=35 \mathrm{~mm}$.

The dimensions of columns are $25 / 100 \mathrm{~cm}$, which are reinforced as shown in the fig. 2 . with $10 \mathrm{R} \square 20$ $\mathrm{mm}+4 \mathrm{R} \square 16 \mathrm{~mm}+2 \mathrm{R} \square 12 \mathrm{~mm}$ in section "3-3" and with $14 \mathrm{R} \square 16 \mathrm{~mm}+2 \mathrm{R} \square 12 \mathrm{~mm}$ in section "4$4 "$.

The minimum cover is $2 \mathrm{~cm}$, so the distance from the bottom of the column to the axis of the bars in fig. 2 section "3-3"will be: $20+8+0,5 \cdot 20=38 \mathrm{~mm}$

While for the column in the section "4-4"will be: $20+8+0,5 \cdot 16=36 \mathrm{~mm}$ 


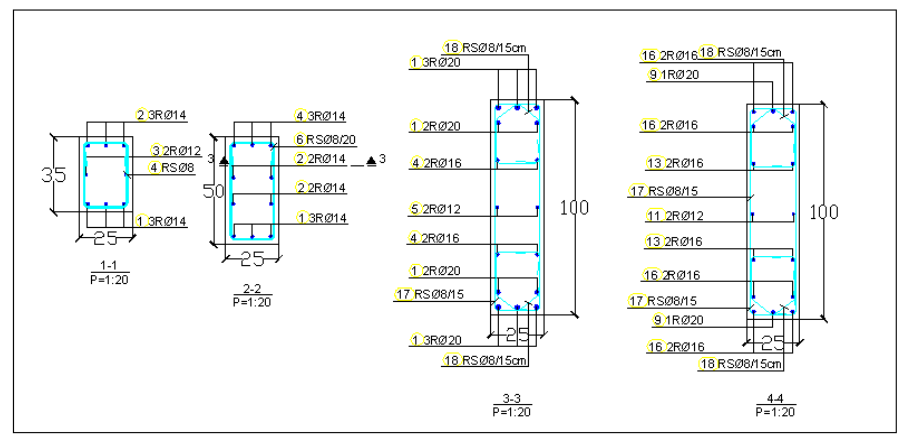

Fig.2. Cross-sections of the beams and columns

\subsection{Accidental situation in fire situation}

Having into consideration only one temporal load, respectively the exploitative one, the combination for the accidental calculation situation is expressed by:

$$
\mathrm{j} \geq 1
$$

$$
\Sigma\left(\mathrm{G}_{\mathrm{k}, \mathrm{j}}\right)+\left(\psi_{11} \text { or } \psi_{2,1}\right) \cdot \mathrm{Q}_{\mathrm{k}, 1}+\mathrm{A}_{\mathrm{d}}
$$

$\mathrm{G}_{\mathrm{kj},}, \mathrm{Q}_{\mathrm{k}, 1}$ characteristic values for the permanent and temporal loads

$\gamma, \gamma_{\mathrm{Q}} \quad$ partial safety factors for permanent actions in the accidental situation $\psi_{11, \psi_{2,1}}$ combination factors for buildings

$\mathrm{A}_{\mathrm{d}} \quad$ design value of the accidental action (in this case actions caused by fire) Expressed wth:

$$
\xi=\mathrm{Q}_{\mathrm{k}, 1} / \mathrm{G}_{\mathrm{k}}
$$

and calculate the reduction factor $\eta_{\mathrm{fi}}$ which represents the connection between the calculation value of the effect of fire and calculation value of the effects during normal temperatures.

$$
\eta_{\mathrm{fi}}=\frac{\mathrm{G}_{\mathrm{k}}+\psi_{11} \cdot \mathrm{Q}_{\mathrm{k}, 1}}{\gamma_{\mathrm{G}} \mathrm{G}_{\mathrm{k}}+\gamma_{\mathrm{Q} 1} \cdot \mathrm{Q}_{\mathrm{k}, 1}}=\frac{\left(\gamma_{\mathrm{GA}+} \psi_{11} \cdot \xi_{1}\right)}{\left(\gamma_{\mathrm{G}+} \gamma_{\mathrm{Q}} \cdot \xi_{1}\right)}=0,59
$$

For $\psi_{1,1=0,5}, \xi_{2}=0.2$ we have: $\eta_{\mathrm{fi}}=0.666$

For $\psi_{2,1=0,3}, \xi_{1=0.51}$ we have: $\eta_{\mathrm{fi}}=0,54, \xi_{2}=0.2 \quad \eta_{\mathrm{fi}}=0.64$

\section{Fire calculation}

\subsection{Equivalent time of fire exposure -(III class of fire load)}

The equivalent time of fire exposure is the neccesary time for the fire that follows the temperaturetime curve to produce the same temperature in the element just like a real fire.The equivalent time of exposure to fire is determined according to:

which is:

$$
\mathrm{t}_{\mathrm{e}, \mathrm{d}}=\mathrm{q}_{\mathrm{f}, \mathrm{d}} \cdot \mathrm{k}_{\mathrm{b}} \cdot \mathrm{w}_{\mathrm{f}} \quad[\min ]
$$

$\mathrm{q}_{\mathrm{f}, \mathrm{d}}$ is the design fire load density $\mathrm{A}_{\mathrm{f}}$ according to annex $\mathrm{E}$

$\mathrm{k}_{\mathrm{b}}$ conversion factor dependent on the thermal characteristics of the circuit

$\mathrm{w}_{\mathrm{f}}$ ventilation factor

where is:

$$
\text { where } \quad \mathrm{q}_{\mathrm{f}, \mathrm{d}}=\gamma_{\mathrm{q}} \gamma_{\mathrm{n}} \cdot \mathrm{q}_{\mathrm{f}, \mathrm{k}}
$$

$\gamma_{\mathrm{q}}$ safety factor that depends on the consequences of the destruction of the structure and impact of the fire taken $\gamma_{q=1.5}$ from the table E.1 in the annex E of EN 1991-1-2 
$\gamma_{\mathrm{n}}$ factor that takes into account the active protective measures against fire, verified firefighting equipments is expressed by $\gamma_{\mathrm{n}=0.6}$

$\mathrm{q}_{\mathrm{f}, \mathrm{k}}$ the value of the characteristic density of the fire load in the compartment unit on the assumption that it is III class fire load may be taken $1000 \mathrm{MJ} / \mathrm{m}^{2}$

$$
\text { namely } \quad \mathrm{q}_{\mathrm{f}, \mathrm{d}}=1.5 \cdot 0.6 \cdot 1000=900 \mathrm{MJ} / \mathrm{m}^{2}
$$

If the thermal characteristics of the environment/circuit were not implemented in details, we take $\mathrm{k}_{\mathrm{b}}=0.07$

$$
\mathrm{W}_{\mathrm{f}}=(6.0 / \mathrm{H})^{0.3}\left[0.62+90\left(0.4-\alpha_{\mathrm{v}}\right]^{4} /\left(1+\mathrm{bv} \cdot \alpha_{\mathrm{h}}\right)\right]>0.5
$$
where :

$$
\alpha_{v}=\mathrm{A}_{\mathrm{v}} / \mathrm{A}_{\mathrm{f}}
$$

with limits: $\quad 0.020<\alpha_{v}<0.20 ; \alpha_{v}=48,405 / 491.84=0,098$

$\alpha_{h}=A_{h} / A_{f}$ ratio of surfaces of horizontal openings $A_{h}$ in roof and surfaces of floor $A_{f}$

$$
\text { bv }=12.5\left(1+10 \alpha_{v}-\alpha_{v}^{2}\right)=12.5\left(1+10 \cdot 0,098-0,098^{2}\right)=24,63>10,0
$$

$\mathrm{H}$ the height of the fireplace $\mathrm{H}=2.7 \mathrm{~m}$,so, the value is:

$$
\mathrm{W}_{\mathrm{f}}=(6.0 / \mathrm{H})^{0.3}\left[0.62+90\left(0.4-0,098 \alpha_{\mathrm{v}}\right]^{4} /(1+24,630)\right]=1.739
$$

and finally, equivalent time of exposure to fire:

$$
\mathrm{t}_{\mathrm{e}, \mathrm{d}}=900 \cdot 0,07 \cdot 1,739=109,56 \mathrm{~min}
$$

\subsection{Comparison of the rated and parametric temperature-time curve}

As regards to fire parametres used in the Item 3.1, we compare the rated temperature-time curve:

$$
\Theta g=20+345 \log _{10}(8 t+1)
$$

The parametric temperature-time curve in the phase of heat is expressed by:

$$
\Theta g=1325\left(1-0.324 \mathrm{e}^{-0,2 \mathrm{t} *}-0,204 \mathrm{e}^{-1,7 \mathrm{t} *}-0.472 \mathrm{e}^{-0,19 \mathrm{t} *}\right)
$$

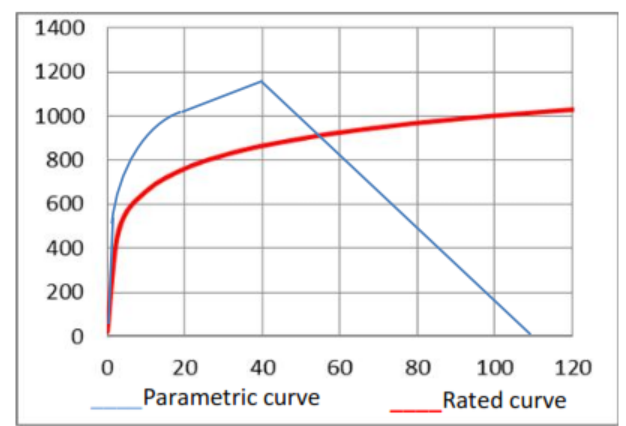

Fig.3. Rated and Parametric temperature time curves

\section{Calculation of fire res istance}

\subsection{Tabulated data design}


The simplest way to verify the fire resistance is the Tabulated data approach.. This method of verification of the fire resistance provides adequate security and does not require taking into account indirect loads or other similar effects.

This access enables to set the minimum dimensions of the cross section and minimum distance of the axis of the rebars to the border of the section , regards to the standard fire curve i.e. $30,60,90,120$, 180 or 240 minutes.

\subsubsection{Beams}

Based on the equivalent time of exposure to fire of $109.56 \mathrm{~min}$, we apply the rated fire resistance R90 as shown in Table 5.6[3] based on which the minimum axial distance for the minimum width of beam of $250 \mathrm{~mm}$ should be a $=25 \mathrm{~mm}$, which in our case is fulfilled : beam $250 \mathrm{~mm} /$ the axial distance 35 $\mathrm{mm}$.

The axial distance $\mathrm{a}_{\mathrm{sd}}$ in cases with one one layer reinforcement should be increased to $10 \mathrm{~mm}$, in our case the $\mathrm{a}_{\mathrm{sd}}=35 \mathrm{~mm}$. This condition is also fulfilled $\mathrm{a}_{\mathrm{sd}}=35 \mathrm{~mm}$,

Consequently, it is not necessary to change the maximum axial distance of beam in order to calculate fire resistance for R90

\subsubsection{Columns}

As regards to rated fire resistance R90, according to the table 3 for the columns exposed to fire in more than one side $b \min =240 \mathrm{~mm}$, the minimum axial distance should be $\mathrm{a}=35 \mathrm{~mm}$, which in our case is fulfilled Table 5.2a [3]-width of the beam $250 \mathrm{~mm} /$ axial distance $36 \mathrm{~mm}$.

As a result: it is not necessary to change the maximum axial distance in order to calculate fire resistance for $\mathrm{R} 90$

\subsubsection{Temperature analysis}

In annex A ,temperature profiles ,of (EN 1992-1-2) the isotherms are given for different cross-section and different specified times under standard heating conditions.In the annex B of the (EN 1992-1-2), we will use the profile with cross-sections $300 \times 600 \mathrm{~mm}$ for the fire resistance R90 and R120.

\subsubsection{Cross-section resistance}

Positive bending moment resistance of the beams may approximately obtained according to Annex E of EN 1992-1-2 by the expression:

where :

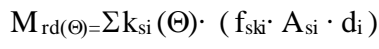

$\mathrm{M}_{\mathrm{rd}(\Theta)}$ is the design resistance to positive bending of the element in the fire situation

$\mathrm{k}_{\mathrm{si}}(\Theta)$ is the reduction factor of the characteristic yield strength of steel rebar i for the given temperature $\Theta$

$f_{\text {ski }}$ is the characteristic yield strength of the rebar $i$ at normal temperature $f_{y k}\left(20^{\circ}\right) C$

$\mathrm{A}_{\text {si }} \quad$ is the nominal section of the rebar $\mathrm{i}$

$\mathrm{d}_{\mathrm{i}} \quad$ is the effective static depth of rebar $\mathrm{i}$

In the diagram from Figure 5.1 of [3], the reduction factor $\mathrm{k}_{\mathrm{si}}(\Theta)$ can be read, for the given temperature

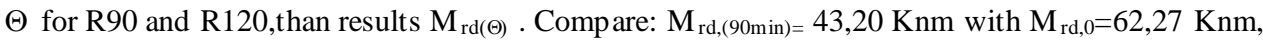

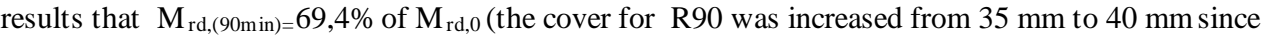
for the case $35 \mathrm{~mm}$ for $\mathrm{M}_{\mathrm{rd},(90 \mathrm{~min})}=59 \%$ of $\mathrm{R} 90 \mathrm{M}_{\mathrm{rd}, 0, \text { in }}$ an analogue manner $\mathrm{M}_{\mathrm{rd},(120 \mathrm{~min})}=78 \%$ of $\mathrm{M}_{\mathrm{rd}, 0}$.

$$
\mathrm{E}_{\mathrm{fi}, \mathrm{d}, \mathrm{t}}=\mathrm{E}_{\mathrm{fi}, \mathrm{d}}=\eta_{\mathrm{fi}}
$$

Calculation value of the effects of fire taking into account $\eta_{\mathrm{fi}}=0,666$ (or 0,64 ) is $66,6 \%$ of $\mathrm{M}_{\mathrm{Ed}, 0}$ or (64\% of $\mathrm{M}_{\mathrm{Ed}, 0)}$ as a result the beams and reinforced bars meet the fire resistance.[4] 


\section{Conclusions}

Upon verification of the resistance of the object $B+G+11$, in order to calculate fire resistance for $\mathrm{R} 120$ it is necessary to change the maximum axial distance of beam and columns. This is achieved by increasing the concrete cover to $40 \mathrm{~mm}$ from the axial distance of the reinforced steel bar to the end of the beam, which is: $40+8+0.5 \times 14=55 \mathrm{~mm}$ and by increasing the concrete cover for columns to 25 $\mathrm{mm}$, the axis of the rebar $\mathrm{R} \phi 20 \mathrm{~mm}$ to the border of the section should be: $25+8+0.5 \times 20=43 \mathrm{~mm}$. In general cases, the application of reinforced steel bars in more than a sequence allows for the possibility that the axial distances are not increased to $10 \mathrm{~mm}$ (although this reduces the cover and extends the necessary surface of the reinforced steel)

The bearing capacity of the building should be preserved in case of fire for a specific time.It could be of interest to get results established by more refined methods .

\section{References}

1. Fire Design of Concrete Structures - materials, structures and modelling. fib bulletin38, Lausanne, Switzerland, April 2007.

2. EN 1991-1-2 Actions on structures-Part1-2:Genaral actions-Actions on structures exposed to fire,European Committee for Standardization, Brussels, November 2002

3. EN 1992-1-2:2004 Design of concrete structures -Part 1- General rules-Structural fire design

4. JURE RADIC Betonske Konstrukcije ,Zagreb,2006 